\title{
12. Leading the Australian Defence Force $^{1}$
}

\author{
Air Chief Marshall Angus Houston AO AFC
}

\section{The basis of successful leadership in the Australian Defence Force}

There are five basic principles that are imperative to the successful leadership of the Australian Defence Force (ADF). The first principle is to provide clear direction. It is necessary to provide a vision, intent and goals that are successfully communicated to other people. If this clear direction is met effectively, people tend to follow you. The second principle is to establish and maintain the right culture, a value-based culture. Values should define the way the leadership in the organisation behaves. If you can establish the right culture in your organisation, goals are much easier to achieve.

The third principle is effective leadership. People demand and require leadership that is focused on people. Therefore, effective leadership is essential when dealing with people. Leadership is also about empowering your people and avoiding micro-management. The fourth principle is communication. Face-to-face communication is the most effective form of leadership and I find that if you engage in this type of communication you get much better results than if you try to lead via the written word.

Finally, the fifth principle is to develop cooperative and harmonious relationships. Having relationships with people in the leadership frame promotes good results and thus relationships are vitally important. Without being able to develop relationships, I would have got absolutely nowhere and, of course, the most important relationship of all for me, in the present context, is the relationship I have with the Secretary of Defence, Nick Warner. This relationship is known as a diarchy and forms a partnership and a very effective form of leadership.

\section{Strategic direction}

The Australian Defence Force needs to be a balanced, networked and deployable force staffed by dedicated and professional people who operate within a culture of adaptability and who excel at joint interagency and coalition operations. At present, every operation the Australian Defence Force conducts is a joint operation and it is imperative that these operations are run in this fashion. Single-service operations are no longer a viable option. The Australian Defence Force needs to be a balanced force with high-end capabilities as this is the ultimate insurance policy in terms of defending the integrity and sovereignty 
of the nation. There are no measured threats to the integrity of Australia as a nation at present, yet maintaining these capabilities is vital to this integrity and sovereignty.

Australia's defence force needs to be able to respond to all challenges in the strategic environment and this requires the ADF to have the ability to perform across the spectrum of operations, across the operational continuum and thus necessitates the need for a balanced force. Australia's experience in recent times demonstrates the need for high-end capabilities, as an ultimate insurance policy, to defend the integrity and sovereignty of the nation. In terms of a deployable force, most of Australia's combat power lives in the south. The north of Australia highlights a substantial deployment challenge. Indeed, operations in Australia's neighbourhood require a substantial deployment and in geographical terms Australia is a long way from the rest of the world. Thus, Australia needs to have a defence force that is able to deploy effectively.

An emphasis on joint interagency and coalition operations needs to be considered. Indeed, Australia has now moved into an era of a focus on interagency collaboration. We need to see all agencies within government working together. If we have a look at some of the stabilisation operations Australia is involved in at the moment, we need to work very closely with our colleagues in the Department of Foreign Affairs and Trade, with AusAID, the Australian Federal Police and, of course, with all the services within the defence force.

And, of course, there are other agencies as well who we have to work with, particularly when we go overseas. Inevitably, we are in some form of coalition and, in my view, this coalition requires a whole-of-agency approach or a whole-of-government approach. I think one of the deficiencies in Afghanistan at the moment is that we do not have a comprehensive whole-of-country approach to the resolution of the problems there. And we need to have the entirety of agencies - military, civilian, government, non-government - all working together cohesively to one common strategy with common goals and objectives.

Let me now move on to our strategic environment because I think it is important to focus on that for the moment. As you would all be aware, we have recently had a change of government, but one thing that is enduring is our strategic environment. It is important to highlight in the first instance that the most fundamental factors that shape our strategic environment concern the relationships between the big powers in our wider region. It is very important for us that the United States, China, Japan and India are able to coexist together in our wider region. I think we can manage the rise of China. Indeed, we are a very lucky nation to be leveraging off the rise of China at the moment. Australia has had 16 years of straight growth and very high levels of growth in our economy and that is due to our relationship with China. 
So China is an important partner to us at the moment. Whilst it grows, it obviously becomes a much bigger and more substantial strategic entity. And as it does that, we do not necessarily have to have strategic competition in the old mould. What we need to do, and what other nations need to do, is manage our relationship with the Chinese so that we can avoid miscalculation and move into the future in a way that is a win-win for all those concerned. If we continue to effectively manage our relationship with China, it will have a positive impact on our prosperity as a nation. Thus, big-power relationships across our region are vitally important.

I might contrast that with some of the issues out there in the Pacific at the moment. If we have a look at what has been happening in the past 12 to 18 months, our region has been challenged by fragility in the smaller nations of the Pacific. Indeed, the crisis in May 2007 in Timor-Leste was testament to this. This fragility is something that we need to respond to and I think the challenges there are substantial. We do not have an easy way of dealing with the challenge of fragile nations out in the Pacific.

One of the challenges is to find a more effective way of dealing with the fragility in the region. Again, I would say, straight away, whilst a military response is quite handy in the first instance, at the end of the day, we need all agencies of the government working together to meet that challenge. The other really big challenge that we face in our neighbourhood and across the world at the moment is the threat of terrorism. We see a very lethal terrorist threat, not only in the Middle East and beyond, but in our own region. Interestingly, we have been very successful against the terrorist threat in our immediate region - particularly the threat that was resident in Indonesia. But it is almost impossible to exterminate it completely. Terrorism will be something we have to deal with into the future. Therefore, we have to find good strategies to deal with what will be an enduring threat in the years ahead. The problem between Israel and her neighbours is something that has to be resolved. Furthermore, we are in Afghanistan at the moment because the country was a haven for terrorists before the coalition became involved.

I might now move on to the operational tempo in the Australian Defence Force. Right now, we have the highest level of operational tempo we have had, certainly, for a generation. And it is probably the most challenging form of operational tempo, in that it extends not just in one area, but in a number of different areas.

If you have a look at what we have done in the past two and a half years, we have had about 20000 individual deployments since July 2004. Compare that with the 20 years from 1980 to 1999. During that time, we were involved in the Gulf War, in the peacekeeping operation in Cambodia as well as in Somalia. Furthermore, at the end of the 1990s, we were involved in the intervention operation in East Timor. In all of those years, with all of those operations, we 
deployed only 17000 individuals. So you can see already in the past two and a half years that we have exceeded the tempo that typified the environment in the 1980s and 1990s. This is highly significant, as the media tends to focus on those people deployed to areas such as Afghanistan, Timor-Leste, Solomon Islands and Iraq. Yet the level of deployment also puts a very heavy load on the defence organisation here in Australia. It does not matter where you go in the defence organisation at the moment, what you will find are very busy people, who are working incredibly hard, in a very dedicated way, so as to ensure that all the enabling support that is required is completed to ensure the success of those operations overseas.

Let me just give you a couple of examples. Our intelligence agencies are probably more stretched than they have ever been. Not only are they providing operational support to areas in which troops have been deployed, they still carry out the workload they would be undertaking in a more normal peacetime environment. Furthermore, if you go to the three services, although the service chiefs are not involved in operations, they and their people provide a vital 'raise, train and sustain' function. Furthermore, the Chief of Army prepares a force to go off to any of the operational deployments and spends six months preparing that force, and that preparation culminates in a full-blown mission rehearsal exercise, which involves not only all the traditional ways of doing business, it includes exploitation of modern technology, mainly simulation, where you are able to actually rehearse and practice everything that you are likely to face when you go on operations.

One of the big threats we face at the moment is improvised explosive devices. We can actually replicate all of that using simulation, so that our troops are very well prepared for the challenge they will face when they go onto operations. I think one of the reasons that we have been very successful on operations is because of that incredible investment that we make in the preparation and training of our people. One of the great things about our troops is their ability to work very closely with whoever we ask them to work with. They get on as well with the Afghans as they do with the Timorese. You can rely on them in very demanding circumstances wherever we deploy them.

\section{Leading the Australian Defence Force}

Seven broad themes define the way I lead the Australian Defence Force. First, I lead with a heavy emphasis on people. People are my highest priority. We have wonderful equipment in the Australian Defence Force, but it's the people who deliver the results. I've just spoken extensively about our people in operations, and if you invest in the right way in training your people, maintaining very high military standards, they deliver incredibly good results. So people are my highest priority, and I will work tirelessly for the welfare of the people of the 
Australian Defence Force, and I expect all of my subordinate commanders to do likewise.

The second broad theme is leadership and values. I will not tolerate any form of poor leadership. This includes any form of bullying, intimidation or coercion. Leadership is about leading by example and treating people in the right way. In terms of the way that we treat people, we should empower people to the maximum extent possible. If you empower people, as I said earlier, you get very good results. Moving on to values, we have a set of values that we emphasise. We expect people to adhere to those values and, of course, the values also define the way we do business in the defence organisation.

The biggest strategic challenge we face in the Australian Defence Force at the moment is recruiting and retaining sufficient people to maintain our capability now and into the future. Our third theme, then, is operations and operational preparedness. If you talk to any chief executive officer around Australia at the moment you will find that this is not a problem that is unique to the Australian Defence Force. Our big problem is in the skilled areas. We are having absolutely no difficulty at the moment recruiting infantry men, but when we come to trying to recruit avionics technicians, electronics technicians, information systems specialists and health specialists, we have a huge problem. And the problem is probably greatest in the navy at the moment. We have 24 critical categories in the navy, three of which are perilous. The problem is a little bit better in the army, with 12 critical categories. The air force at present has no critical categories, although in the past three months, with the shortage of pilots worldwide, we have been starting to see very high separation rates with our pilots. And, indeed, right now, we have a separation rate of just fewer than 40 per cent for pilots who are not held by a return of service obligation. And, of course, they are our most experienced pilots - the people who instruct and lead in the flying game. Thus, we are taking steps to address that particular problem, which has come almost out of nowhere. We knew it was going to come at some stage. It is amazing what traction we have seen in recent times. And this reflects a shortage of pilots right across Australia at the moment and, indeed, right across the world. Fortunately, we have a 10-year return of service obligation on pilot courses, so we are not in a critical state, but we certainly have to address the problem and we are addressing that problem right now.

In the long term, I think we are going to be and will continue to be challenged by getting sufficient people into the defence force in all three services. If you have a look at the demographics, they are against us. And with a booming economy, with unemployment running at or about 4 per cent, it is a huge challenge to recruit sufficient people for the defence force. I am pleased to say that our performance in 2006 improved quite dramatically. We obtained just over 90 per cent enlistment, which was a marked improvement on the year 
before and the best result we have had for quite a few years. But we had to work incredibly hard to achieve that result. An area that I think we have to improve is in the retention area. In order to improve in this area we need to get our separation rates down to where the air force is at the moment, which is down below 10 per cent. Both navy and army have separation rates that are a little higher than I'm comfortable with.

A couple of areas I would just like to highlight on the way through are the military justice reforms. We are well advanced in the implementation of those reforms and indeed we would almost have the program finished now but for the fact that the election was called and some of the final pieces of the legislation were caught up due to the fact that the Parliament ceased and we did not get the final bit of legislation through. This will be readdressed with the new government.

In terms of operations, just to give you some facts about what is happening right now with our relief operation in Papua New Guinea, we have just fewer than 200 people in Papua New Guinea. Furthermore, at the moment, we have 4500 people deployed on operations. I think this reflects just what a high level of operational tempo we have. Of course, that also includes the 450-500 or so people who are involved in boarder security operations in northern Australia and of course the people who are involved in the Northern Territory emergency task force.

In terms of the fourth theme, strategic direction, I know many of you would be interested in that. We look forward to being involved in the writing of a new white paper. The last white paper process was conducted in 1999-2000 with the white paper published in 2000. The new government has made it very clear that in 2008 we will be embarking on another white paper process and it is very important that we seize the opportunity to review all parts of our organisation and of course conduct a thorough review of our strategic environment. That is probably the most important part of the work- to review our strategic environment and then, after we have reviewed this, look at the capabilities that are required within the full structure of the defence force. We need to have a look at all parts of the defence organisation, including the infrastructure, the information systems - indeed, everything that gives us the capability to do what government requires of us. And I relish the opportunity to be involved in that really important process.

One of the things that I wanted to do when I first came to the job of Chief of the Defence Force was to establish a good strategic framework so that we had clear direction as to where we were going. This has produced a very highly classified and very good document called the Defence Planning Guidance. Clearly, it will have to be updated as part of the white paper process, but it really provides the basis for a number of other strategic documents that guide the way we do 
business in the defence force. I am very pleased with where we are at with that documentation at the moment.

The fifth theme is capability. We have been very heavily involved in the investment in new capability in the past few years. I anticipate that out of the white paper process we will do another capability review and out of that will come another Defence Capability Plan. Again, I think that is going to be very important because it is absolutely imperative that we continue to invest in new capability to take us into the future. Whilst we are well placed at the moment, there is still much work to be done and, of course, the capability that we acquire needs to be the right capability for the strategic circumstances that are defined in the white paper. Because we are a nation of just over 21 million people, it is very important that we make the right decisions in that particular area. Over the years, governments of both sides have been very effective in coming up with the right force structure to give us the balance we need to face the strategic challenges that Australia has seen.

The sixth theme is based on collaborative relationships. Relationships across government are vitally important. I remember years ago we probably used to work in our stove pipes. I think the stove, the departmental stove pipes, are gone for good. It is absolutely imperative that we work across government in a very effective way and I think some of the forums that have been established, some of the committees that have been established, have seen us do much better work. Probably the best of those in my view is the National Security Committee in cabinet. I think that is a very effective way of running the national security business of government. That particular committee brings together not only the responsible minister, but the responsible officials in a very effective way of dealing with complex national security issues from the crisis that has just broken to the very important capability decisions that I have mentioned above.

Finally, the seventh theme is management, governance and accountability. Right now we are occupied with the business of implementing the Proust Report. ${ }^{2}$ This is well under way. We have hit most of the high points, we are implementing all of the recommendations other than the one to do away with the diarchy. ${ }^{3}$ Secretary Warner and I think the organisation works fine under our partnership, under our joint leadership and the areas that we are focused on are obviously improving advice to government, which is a high priority, improving our information technology systems and also rationalising some of the structures within the defence organisation. What we are doing is separating the policy part of human resources in the defence personnel executives from service delivery. We are moving service delivery functions out into the defence support group and we think that will give us a much more effective way of developing human resource policy. 
One of the areas that I think has worked well as part of the reforms is separating the vice chief and the chief of joint operations functions. The vice chief will work in a number of areas that are important to improving governance and also improving the way we look after joint capability. We will have a three-star officer, General David Hurley, who will be initially at Fairbairn, but later out in our new headquarters in Bungendore and he will have total responsibility to run our operations. We have found with this very high level of operational tempo that it is imperative to have an officer who concentrates wholly and solely on operations. And already we are seeing the benefit of the split that was implemented about two or three months ago.

The final part of the Proust Report is improving our accountabilities. Because we are a very large organisation, sometimes the accountabilities have become a bit blurred. We will be looking at accountabilities and coming up with a much better way of doing business to ensure that everybody knows exactly what their accountabilities are, that they are not lost in this rather large and complex organisation that we call the defence organisation.

\section{Conclusion}

In conclusion, you can be very, very proud of your defence organisation and you can be particularly proud of those young people that we send off into harm's way to do the business the government has asked them to do. They always excel in the operational environment, they have great generosity of spirit, they are very courageous but they are also very compassionate and they represent Australia in a very fine way.

\section{ENDNOTES}

1 This essay was originally presented as an ANZSOG Public Lecture on 28 November 2007.

2 Proust, Elizabeth (2007), Report of the Defence Management Review 2007. Australian Government, Department of Defence, Canberra. The Defence Management Review was established by the Minister for Defence on 18 August 2006 to review and make recommendations in relation to 'Defence decision making, business processes, human resources, finance and information management processes and systems'.

3 The Proust Report observed that 'The most unusual part of the Defence model is the diarchy, under which the Secretary and the CDF share responsibility and accountability for most of the functions in Defence' (p. 8:2.3). The report states that the Diarchy 'describes the joint leadership of Defence by the Secretary and CDF, both under the Minister for Defence. Within the diarchy, the Secretary and CDF are responsible for "joint administration" of the ADF. The CDF commands the ADF and is the principal military adviser to the Minister' (p. 30:5.6). The review 'formed the view that the diarchy, and the reality of a two-headed organisation, leads to a diffusion of commitment to and compliance with leadership visions and goals throughout the organisation. Moreover, achieving consistency in articulating a vision and strategy will always be more difficult in a diarchy than in an organisation with one leader' (p. 19:4.16). Although the review stated that 'we believe that the diarchy is still an appropriate way to run what is the most complex portfolio in Government' (p. 41:5.10) it nevertheless made two recommendations (Recommendations 17 and 18) aimed at giving 'greater definition to the individual and shared roles of the CDF and Secretary in the diarchy' (R17, p. 49). Neither recommendation was accepted in the Department of Defence response to the recommendations arising from the Defence Management Review ( http://www.defence.gov.au/dmr/defence_response.pdf 
http:/true/truewww.defence.gov.au/truedmr/truedefence_response.pdf), and it is these recommendations Angus Houston is referring to here. (Editor's note). 